\title{
Extrafine triple therapy in patients with symptomatic COPD and history of one moderate exacerbation
}

\author{
To the Editor:
}

In chronic obstructive pulmonary disease (COPD), exacerbation history is the strongest predictor of future exacerbation risk [1,2]. Large cohort studies have shown that patients with one exacerbation in the previous year have an approximately two-fold increased future exacerbation risk compared to patients with no exacerbations, the risk increasing to five-fold in those with two or more exacerbations [1, 2]. Most clinical trials of pharmacological treatments designed to prevent exacerbations have therefore used the inclusion criterion of at least one exacerbation in the previous year, with a minority requiring at least two exacerbations [3-6].

The Global Initiative for Chronic Obstructive Lung Disease (GOLD) report advocates the "ABCD" classification after initial diagnosis to identify patients at high risk of exacerbations, using the criteria of two or more exacerbations requiring systemic corticosteroids and/or antibiotics ("moderate exacerbations") or a single exacerbation leading to hospitalisation ("severe exacerbation") in the previous year [7]. The 2019 GOLD update provides treatment algorithms for follow-up therapy, with inhaled corticosteroid (ICS)-containing (double or triple) combinations recommended for patients who continue to have exacerbations [8]. However, a gap in the evidence is whether the addition of ICS provides a clinical benefit in patients who have just one moderate exacerbation in the past year despite receiving maintenance treatment.

A single triple combination inhaler containing an extrafine formulation of the ICS beclometasone dipropionate (BDP), the long-acting $\beta_{2}$-agonist (LABA) formoterol fumarate (FF) and the long-acting muscarinic antagonist (LAMA) glycopyrronium $(\mathrm{G})$ has been developed to simplify therapy in patients with COPD, whilst ensuring efficient lung delivery of all three molecules. TRILOGY, TRINITY and TRIBUTE were three 52-week studies that evaluated the efficacy and safety of BDP/FF/G compared with $\mathrm{BDP} / \mathrm{FF}$ (TRILOGY), tiotropium and BDP/FF plus tiotropium (TRINITY), and the fixed-dose combination of indacaterol and glycopyrronium (IND/GLY) (TRIBUTE) [3-5]. All three studies recruited symptomatic patients (COPD Assessment Test total score $\geqslant 10$ ) with a history of at least one moderate-to-severe exacerbation, post-bronchodilator forced expiratory volume in $1 \mathrm{~s}$ (FEV1) $<50 \%$ of predicted and who were receiving maintenance inhaled therapy for at least 2 months prior to entry with long-acting bronchodilator monotherapy or dual combination therapy but not triple therapy; this population therefore allowed an investigation of step-up to triple therapy.

Here we report the results of post hoc analyses of the efficacy and safety of extrafine BDP/FF/G in the subgroup of patients with symptomatic COPD, severe or very severe airflow limitation, and a history of one moderate exacerbation despite maintenance therapy; patients with any exacerbation resulting in an emergency department visit or hospitalisation were excluded.

The designs and results of TRILOGY, TRINITY and TRIBUTE have been previously published [3-5]. Briefly, during the 2-week run-in, all patients received BDP/FF in TRILOGY, tiotropium in TRINITY, and IND/GLY in TRIBUTE. The studies then randomised one group of patients to receive extrafine BDP/FF/G $87 / 5 / 9 \mu \mathrm{g}(100 / 6 / 10 \mu \mathrm{g}$ ex valve) two puffs twice daily via pressurised metered dose inhaler (pMDI). The comparator groups were: TRILOGY, extrafine BDP/FF $87 / 5 \mu \mathrm{g}(100 / 6 \mu \mathrm{g}$ ex valve), two puffs twice daily

@ERSpublications

In patients with symptomatic COPD, severe/very severe airflow limitation, and a history of one moderate (and no severe) exacerbation, ICS-containing triple therapy significantly reduces exacerbation risk overall versus single or double maintenance therapy http://ow.ly/VgJC30o9pXC

Cite this article as: Singh D, Fabbri LM, Corradi M, et al. Extrafine triple therapy in patients with symptomatic COPD and history of one moderate exacerbation. Eur Respir J 2019; 53: 1900235 [https://doi. org/10.1183/13993003.00235-2019]. 
via pMDI; TRINITY, tiotropium $18 \mu \mathrm{g}$ once daily via single-dose dry powder inhaler (SDDPI), or extrafine BDP/FF $87 / 5 \mu \mathrm{g}$ two puffs twice daily via pMDI plus tiotropium $18 \mu \mathrm{g}$ once daily via SDDPI; TRIBUTE, IND/GLY $85 / 43 \mu \mathrm{g}(110 / 50 \mu \mathrm{g}$ per capsule) one puff once daily via SDDPI. The studies are registered in ClinicalTrials.gov: TRILOGY, NCT01917331; TRINITY, NCT01911364; TRIBUTE, NCT02579850. Pre-dose morning FEV1 and St George's Respiratory Questionnaire (SGRQ) were assessed at baseline and weeks $4,12,26,40$ and 52, with moderate-to-severe exacerbations assessed over the study duration. The number of moderate/severe COPD exacerbations was analysed using a negative binomial model. FEV1 and SGRQ mean changes from baseline were evaluated using a linear mixed model for repeated measures, with a logistic regression model used to analyse SGRQ responders. The statistical models used were consistent with the overall study analyses [3-5]. The number needed to treat (NNT) was calculated for exacerbations: both event-based (the NNT for 1 year with BDP/FF/G rather than the comparator to prevent one moderate/severe COPD exacerbation) and person-based (the NNT for 1 year with $\mathrm{BDP} / \mathrm{FF} / \mathrm{G}$ rather than the comparator to prevent one patient from experiencing any exacerbation).

a)

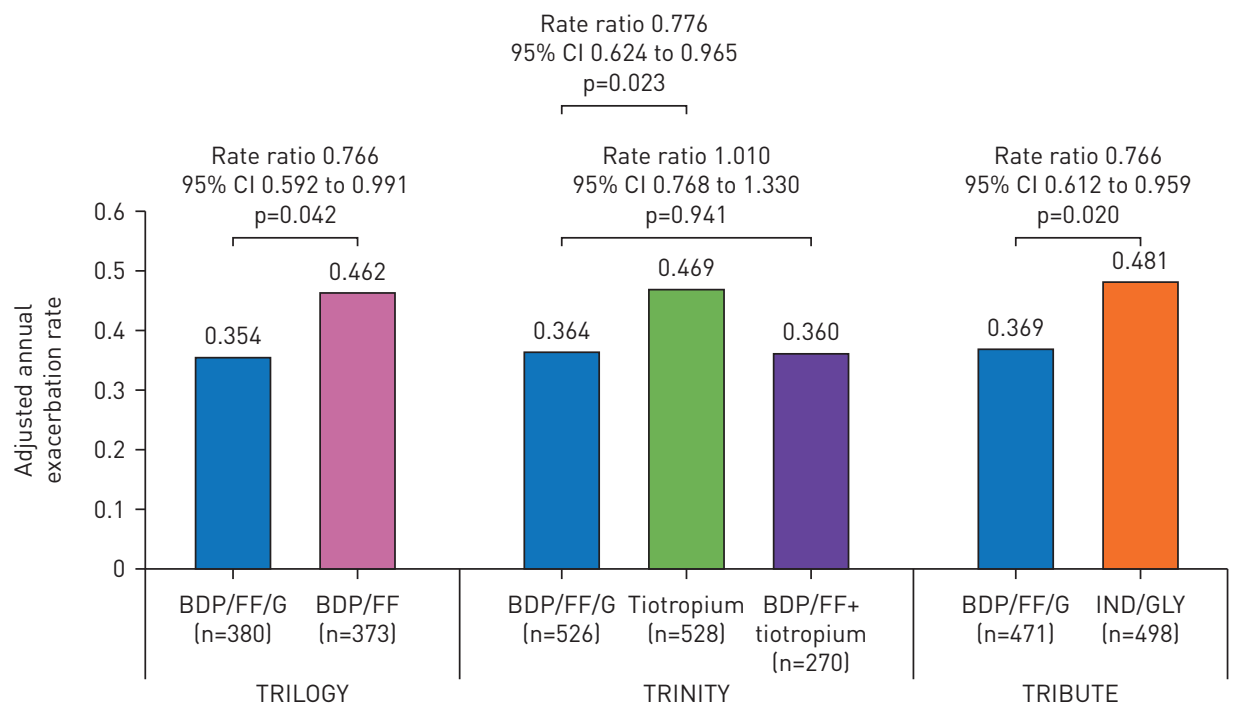

b)

\begin{tabular}{|c|c|c|c|c|}
\hline & \multirow{3}{*}{$\begin{array}{c}\text { TRILOGY } \\
\text { BDP/FF/G (n=380) } \\
\text { versus } \\
\text { BDP/FF (n=373) }\end{array}$} & \multicolumn{2}{|c|}{ TRINITY } & \multirow{3}{*}{$\begin{array}{c}\text { TRIBUTE } \\
\text { BDP/FF/G (n=471) } \\
\text { versus } \\
\text { IND/GLY (n=498) }\end{array}$} \\
\hline & & \multicolumn{2}{|c|}{$\mathrm{BDP} / \mathrm{FF} / \mathrm{G}(\mathrm{n}=526)$ versus } & \\
\hline & & $\begin{array}{c}\text { Tiotropium } \\
\text { (n=528) }\end{array}$ & $\begin{array}{c}\text { BDP/FF + tiotropium } \\
(n=270)\end{array}$ & \\
\hline \multicolumn{5}{|l|}{$\begin{array}{l}\text { Week } 52 \text { SGRQ } \\
\text { total score }\end{array}$} \\
\hline Mean & $\begin{array}{c}-3.97(-5.92 \text { to }-2.02) \\
p<0.001\end{array}$ & $\begin{array}{c}-1.43(-3.12 \text { to } 0.26) \\
p=0.098\end{array}$ & $\begin{array}{c}1.64(-0.39 \text { to } 3.68) \\
p=0.114\end{array}$ & $\begin{array}{c}-2.14(-3.63 \text { to }-0.65) \\
p=0.005\end{array}$ \\
\hline Responders & $\begin{array}{c}1.54(1.14 \text { to } 2.09) \\
p=0.006\end{array}$ & $\begin{array}{c}1.22(0.94 \text { to } 1.58) \\
p=0.133\end{array}$ & $\begin{array}{c}0.92(0.67 \text { to } 1.26) \\
p=0.604\end{array}$ & $\begin{array}{c}1.38(1.05 \text { to } 1.80) \\
p=0.020\end{array}$ \\
\hline $\begin{array}{l}\text { Overall mean SGRQ } \\
\text { total score }\end{array}$ & $\begin{array}{c}-2.91(-4.29 \text { to }-1.52) \\
p<0.001\end{array}$ & $\begin{array}{c}-1.86(-3.10 \text { to }-0.62) \\
p=0.003\end{array}$ & $\begin{array}{c}0.51(-1.00 \text { to } 2.01) \\
p=0.509\end{array}$ & $\begin{array}{c}-2.16(-3.23 \text { to } 1.08) \\
p<0.001\end{array}$ \\
\hline $\begin{array}{l}\text { Week } 52 \text { pre-dose } \\
\text { morning FEV } 1 \mathrm{~mL}\end{array}$ & $\begin{array}{c}83(42 \text { to } 123) \\
p<0.001\end{array}$ & $\begin{array}{c}52(16 \text { to } 88) \\
p=0.005\end{array}$ & $\begin{array}{c}-16(-59 \text { to } 27) \\
p=0.470\end{array}$ & $\begin{array}{l}25(-5 \text { to } 55) \\
\quad p=0.103\end{array}$ \\
\hline $\begin{array}{l}\text { Overall pre-dose } \\
\text { morning FEV } \mathrm{mL}\end{array}$ & $\begin{array}{c}93(62 \text { to } 124) \\
p<0.001\end{array}$ & $\begin{array}{c}41(13 \text { to } 68) \\
p=0.003\end{array}$ & $\begin{array}{c}-26(-58 \text { to } 7) \\
p=0.128\end{array}$ & $\begin{array}{c}28(6 \text { to } 51) \\
p=0.014\end{array}$ \\
\hline
\end{tabular}

FIGURE 1 a) Adjusted annual rate of moderate-to-severe chronic obstructive pulmonary disease exacerbations (intention-to-treat population). b) Between-treatment differences in St George's Respiratory Questionnaire (SGRQ) total score and forced expiratory volume in $1 \mathrm{~s}$ (FEV 1 ) at week 52 and overall, and SGRQ responders at week 52 (intention-to-treat population). Data are adjusted mean differences or odds ratios with $95 \%$ confidence intervals and $p$-values. SGRQ responders are patients with a decrease from baseline in SGRQ total score of at least 4 units. BDP: beclometasone dipropionate; FF: formoterol fumarate; G: glycopyrronium; IND/GLY: indacaterol/glycopyrronium. 
The subgroup of patients with one moderate exacerbation in the previous 12 months represented 55.1\%, $49.2 \%$ and $63.3 \%$ of the overall population in TRILOGY, TRINITY and TRIBUTE, respectively. There were no substantial differences between groups in baseline demographics or disease characteristics, either within or among the three studies. The majority of patients ( $82.0 \%$ overall) included in the analyses had severe airflow limitation (FEV1 30-50\% predicted).

The effect of BDP/FF/G on moderate-to-severe exacerbations was consistent across the three studies, with a $23 \%$ reduction versus BDP/FF (TRILOGY), a $22 \%$ reduction versus tiotropium (TRINITY), and a $23 \%$ reduction versus IND/GLY (TRIBUTE) (figure 1a). The event-based NNTs were nine, 10 and nine for $\mathrm{BDP} / \mathrm{FF} / \mathrm{G}$ versus $\mathrm{BDP} / \mathrm{FF}$, tiotropium and IND/GLY, respectively, with person-based NNTs of 16,87 and 26 , respectively. BDP/FF/G provided significantly greater improvements in SGRQ total score versus BDP/FF and IND/GLY overall (i.e. averaged from all study visits) and at week 52, and versus tiotropium overall (figure 1b). Patients receiving BDP/FF/G were significantly more likely to be SGRQ responders at week 52 than those receiving BDP/FF or IND/GLY (figure $1 \mathrm{~b}$ ). In TRINITY, the proportion of SGRQ responders to $\mathrm{BDP} / \mathrm{FF} / \mathrm{G}$ was higher compared to tiotropium, but the odds ratio was not statistically significant. BDP/ $\mathrm{FF} / \mathrm{G}$ also provided significantly greater improvements in lung function (pre-dose morning FEV1) versus $\mathrm{BDP} / \mathrm{FF}$ and tiotropium overall and at week 52 and versus IND/GLY overall (figure 1b).

Overall, the incidence of adverse events was similar for BDP/FF/G compared to the other treatments (50.8-61.4\% for BDP/FF/G, 50.9\% for BDP/FF, 55.8\% for tiotropium, 57.0\% for BDP/FF plus tiotropium, and $68.5 \%$ for IND/GLY). The incidence of pneumonia was low, and apart from tiotropium monotherapy in TRINITY, was similar across treatment groups including IND/GLY in TRIBUTE $(2.3-3.2 \%$ for BDP/FF/G, $2.1 \%$ for BDP/FF, $0.8 \%$ for tiotropium, $1.5 \%$ for BDP/FF plus tiotropium, and 3.2\% for IND/GLY).

The results of these post hoc analyses in patients with symptomatic COPD, severe or very severe airflow limitation, and who had one moderate exacerbation in the previous year despite receiving regular inhaled maintenance therapy with single long-acting bronchodilator or dual combination therapy prior to entering the study, showed that inhaled triple therapy with extrafine BDP/FF/G provided clinical benefits compared with LAMA, ICS/LABA and LABA/LAMA. Of note, these effects were observed on the important clinical end-points of exacerbations and health-related quality of life, along with FEV1. These analyses therefore provide guidance on therapy for this group of patients often considered not at high risk of future exacerbations. GOLD does not define a level of exacerbations at which treatment escalation should occur; our results provide evidence to support the use of triple therapy even at the threshold level of only one moderate exacerbation, although we acknowledge that these are mean data, and there is variation between individuals.

The perception that the GOLD ABCD grouping has inadvertently created is that only patients with at least two exacerbations or one exacerbation resulting in hospitalisation require pharmacological treatments to prevent future exacerbations. This overlooks the substantial heterogeneity within COPD. Our results emphasise the importance of considering both the clinical characteristics and current therapy when selecting alternative treatment options for patients with COPD.

Dave Singh ${ }^{1}$, Leonardo M. Fabbri $\circledast^{2,3}$, Massimo Corradi $^{4}$, George Georges ${ }^{5}$, Alessandro Guasconi ${ }^{6}$, Stefano Vezzoli ${ }^{6}$, Stefano Petruzzelli ${ }^{6}$ and Alberto Papi $\odot^{2}$

${ }^{1}$ Medicines Evaluation Unit, University of Manchester, Manchester University NHS Foundation Trust, Manchester, UK. ${ }^{2}$ Section of Cardiorespiratory and Internal Medicine, Dept of Medical Sciences, University of Ferrara, Ferrara, Italy. ${ }^{3}$ COPD Center, Institute of Medicine, Sahlgrenska University Hospital, University of Gothenburg, Gothenburg, Sweden. ${ }^{4}$ Dept Medicine and Surgery, University of Parma, Parma, Italy. ${ }^{5}$ Global Clinical Development, Chiesi USA, Inc., Cary, NC, USA. ${ }^{6}$ Global Clinical Development, Chiesi Farmaceutici SpA, Parma, Italy.

Correspondence: Dave Singh, University of Manchester, Medicines Evaluation Unit, Manchester, M23 9QZ, UK. E-mail: dsingh@meu.org.uk

Received: Jan 242019 | Accepted after revision: Feb 122019

The TRILOGY, TRINITY and TRIBUTE studies are registered at ClinicalTrials.gov as NCT01917331, NCT01911364 and NCT02579850, respectively.

Acknowledgements: The three studies described in this manuscript were funded by Chiesi Farmaceutici SpA, as were the analyses presented here. Writing support was provided by David Young of Young Medical Communications and Consulting Ltd. This support was funded by Chiesi Farmaceutici SpA.

Conflict of interest: D. Singh reports personal fees from Chiesi, during the conduct of these studies; grants and personal fees from Almirall, AstraZeneca, Boehringer Ingelheim, Chiesi, GlaxoSmithKline, Glenmark, Johnson and Johnson, Merck, NAPP, Novartis, Pfizer, Takeda, Teva, Theravance and Verona, personal fees from Genentech and Skeypharma, outside the submitted work. L.M. Fabbri reports personal fees and non-financial support from AstraZeneca, GSK, Novartis, Menarini, Boehringer Ingelheim, Zambon and Pearl Therapeutics, grants, personal fees and non-financial support from Chiesi, non-financial support from Dompe, outside the submitted work. M. Corradi reports grants and 
personal fees from Chiesi Farmaceutici SpA, outside the submitted work. G. Georges was an employee of Chiesi USA, Inc., during the conduct of these studies. A. Guasconi was an employee of Chiesi Farmaceutici S.p.A, during the conduct of these studies. S. Vezzoli was an employee of Chiesi Farmaceutici S.p.A, during the conduct of these studies. S. Petruzzelli was an employee of Chiesi Farmaceutici S.p.A, during the conduct of these studies. A. Papi reports fees for board membership, consultancy, payment for lectures, grants for research and travel expenses reimbursement from Chiesi, AstraZeneca, GlaxoSmithKline, Boehringer Ingelheim, Mundipharma and TEVA, fees for lectures and travel expenses reimbursement from Menarini, Novartis and Zambon, grants for research from Sanofi, outside the submitted work.

Support statement: The analyses presented here were funded by Chiesi Farmaceutici SpA. D. Singh is supported by the National Institute for Health Research (NIHR) Manchester Biomedical Research Centre (BRC). Funding information for this article has been deposited with the Crossref Funder Registry.

\section{References}

1 Hurst JR, Vestbo J, Anzueto A, et al. Susceptibility to exacerbation in chronic obstructive pulmonary disease. N Engl J Med 2010; 363: 1128-1138.

2 Han MK, Quibrera PM, Carretta EE, et al. Frequency of exacerbations in patients with chronic obstructive pulmonary disease: an analysis of the SPIROMICS cohort. Lancet Respir Med 2017; 5: 619-626.

3 Singh D, Papi A, Corradi M, et al. Single inhaler triple therapy versus inhaled corticosteroid plus long-acting $\beta 2$-agonist therapy for chronic obstructive pulmonary disease (TRILOGY): a double-blind, parallel group, randomised controlled trial. Lancet 2016; 388: 963-973.

4 Vestbo J, Papi A, Corradi M, et al. Single inhaler extrafine triple therapy versus long-acting muscarinic antagonist therapy for chronic obstructive pulmonary disease (TRINITY): a double-blind, parallel group, randomised controlled trial. Lancet 2017; 389: 1919-1929.

5 Papi A, Vestbo J, Fabbri L, et al. Extrafine inhaled triple therapy versus dual bronchodilator therapy in chronic obstructive pulmonary disease (TRIBUTE): a double-blind, parallel group, randomised controlled trial. Lancet 2018; 391: 1076-1084.

6 Lipson DA, Barnhart F, Brealey N, et al. Once-daily single-inhaler triple versus dual therapy in patients with COPD. N Engl J Med 2018; 378: 1671-1680.

7 Vogelmeier CF, Criner GJ, Martinez FJ, et al. Global Strategy for the Diagnosis, Management, and Prevention of Chronic Obstructive Lung Disease 2017 Report: GOLD Executive Summary. Eur Respir J 2017; 49: 1700214.

8 Global Initiative for Chronic Obstructive Lung Disease. Global Strategy for the Diagnosis, Management, and Prevention of Chronic Obstructive Pulmonary Disease. 2019. https://goldcopd.org Date last accessed: January 24, 2019. 